1 Research Journal of Accounting and Business Management (RJABM); P-ISSN: 2580-3115; E-ISSN: 2580-3131

\title{
KEPUTUSAN PEMBELIAN ASURANSI JIWA PADA KONSUMEN RURAL: PENGARUH BAURAN PEMASARAN JASA
}

\author{
Silvana Kardinar Wijayanti
}

\author{
Sekolah Tinggi Ilmu Ekonomi Tenggarong \\ Jalan Wolter Monginsidi no. 25, Tenggarong, Kaltim \\ silvana.dinar@gmail.com
}

\begin{abstract}
Indonesia is one of the most promising markets for the growth of life insurance business in Southeast Asia. Low penetration rate and huge population that is scattered in many islands emerge as opportunity and challenge for any company that is willing to operate its insurance business in this country. This study aims to examine the effects of services marketing mix namely product, price, place, promotion, people, process and physical evidence on life insurance purchase decision of rural customers in Kutai Kartanegara Regency, East Kalimantan Province. Data collected through self-administered survey to 76 life insurance policyholders in 3 sub-districts in Kutai Kartanegara Regency such as Tenggarong, Kota Bangun and Sebulu that represented cluster-rural area of East Kalimantan. Multiple linear regression model was used to analyze the data and the results revealed that product, price, people, and physical evidence positively and significantly affect life insurance purchase decision, while place shown negative and significant effect. On the other hand, we found that promotion and process do not significantly affect purchase decision on life insurance.
\end{abstract}

Keywords: Life insurance, Purchase decision, Rural market, Service marketing mix

\section{PENDAHULUAN}

Di setiap ketidakpastian selalu ada resiko. Begitu pula dengan hidup manusia. Resiko hidup seperti meninggal, sakit, kecelakaan, cacat, dan kehidupan di masa pesiun adalah sesuatu yang tidak dapat diprediksi kapan, bagaimana dan di mana terjadinya, namun ketika resiko-resiko hidup tersebut terjadi, kondisi finansial seseorang atau suatu keluarga dapat dipastikan bermasalah. Asuransi jiwa adalah usaha jasa keuangan non-bank yang berfungsi sebagai lembaga pengalihan resiko dengan mengumpulkan dana nasabah dan menyediakan perlindungan terhadap resiko hidup (Cordell dan Langdon, 2009). 
Di Indonesia, asuransi jiwa masih belum dianggap sebagai produk yang penting. Kesadaran masyarakat akan pentingnya asuransi jiwa masih terbilang rendah. Hal ini tercermin dari rendahnya rasio masyarakat yang berasuransi, yaitu kurang dari $10 \%$ dari total penduduk Indonesia yang mencapai 260 juta jiwa. Namun bagi perusahaan dan para pemasar rendahnya penetrasi pasar berarti masih luasnya peluang untuk mengembangkan bisnis asuransi jiwa di negara ini. Indonesia adalah salah satu negara yang paling menjanjikan untuk pertumbuhan bisnis asuransi jiwa di kawasan Asia Tenggara. Hal ini membuat persaingan menjadi sangat sengit. Beberapa tahun terakhir banyak perusahaan asuransi jiwa asing yang ikut menjajal peruntungannya di industri asuransi jiwa Indonesia (Kulsum, 2018; Windarto, 2017). Agar memenangkan persainagn dan menghasilkan program pemasaran yang efektif dan efisien pemasar perlu mengidentifikasi variabel-variabel yang mempengaruhi keputusan pembelian asuransi jiwa.

Bauran pemasaran merupakan alat yang sering digunakan perusahaan dalam menciptakan strategi pemasaran. Menurut Kotler dan Amstrong (2010:51), bauran pemasaran adalah seperangkat alat taktik pemasaran yang dipadukan oleh perusahaan untuk menghasilkan tanggapan yang diinginkan dari pasar sasaran. Dalam pemasaran jasa dikenal ada 7 variabel bauran pemasaran yang terdiri dari product (produk), price (harga), place (tempat), promotion (promosi), people (orang), process (proses), dan physical evidence (bukti fisik).

Pengaruh bauran pemasaran terhadap keputusan pembelian telah banyak dipelajari oleh akademisi dan pebisnis di bidang pemasaran. Berdasarkan hasil temuan mereka, dapat disimpulkan bahwa bauran pemasaran mempunyai pengaruh yang signifikan terhadap keputusan pembelian, namun besarnya pengaruh variabel-variabel bauran pemasaran terhadap keputusan pembelian dan variabel yang muncul sebagai variabel dominan berbeda-beda setiap penelitian tergantung kategori produk yang diteliti, lokasi penelitian, karakteristik responden dan lain sebagainya (Dastak dan Aligholi, 2014; Lilianti 2013; Sukotjo dan Radix A., 2010). Kendatipun demikian, penelitian tentang pengaruh bauran pemasaran terhadap keputusan pembelian yang fokus kepada konsumen rural masih jarang dilakukan di Indonesia.

Di sisi lain, pemasaran rural mulai menjadi fokus para pebisnis dan akademisi di Indonesia. Jumlah penduduk rural yang besar dan bertumbuh secara finansial namun 
cenderung kurang terjamah dan tidak memiliki banyak tempat untuk mendisposisi uang mereka, membuat pasar rural sangat menarik bagi para pebisnis. Razdan, et.al (2013) menyatakan bahwa meskipun urbanisasi di Indonesia diperkiakan meningkat, namun jumlah populasi penduduk rural saat ini masih sangat signifikan, yaitu 110 juta jiwa. Walaupun berada pada tren menurun, populasi rural diperkirakan berjumlah lebih dari 80 juta jiwa pada 2030 nanti, dan berkontribusi sebesar $14 \%$ terhadap GDP.

\section{Rumusan Masalah}

Berdasarkan paparan di atas, maka dapat dibuat beberapa rumusan masalah penelitian sebagai berikut:

1. Apakah bauran pemasaran jasa yang terdiri dari product (X1), price (X2), place (X3), promotion (X4), people (X5), process (X6) dan physical evidence (X7) berpengaruh positif terhadap keputusan pembelian asuransi jiwa pada konsumen rural ?

2. Dari tujuh variabel bauran pemasaran jasa, manakah variabel yang muncul dominan mempengaruhi keputusan pembelian asuransi jiwa pada konsumen rural?

\section{Tujuan Penelitian}

Maka tujuan dari penelitian ini adalah sebagai berikut:

a. Untuk menguji dan menganalisis pengaruh variabel bauran pemasaran jasa yang terdiri dari produk (X1), harga (X2), tempat (X3), promosi (X4), orang (X5), proses (X6) dan bukti fisik (X7) terhadap keputusan pembelian asuransi jiwa pada konsumen rural.

b. Untuk mengidentifikasi variabel yang dominan mempengaruhi keputusan pembelian asuransi jiwa pada konsumen rural.

\section{TINJAUAN PUSTAKA}

\section{Pemasaran Jasa}

Pemasaran merupakan tonggak penghasilan perusahaan. Sebaik apapun produk yang dihasilkan perusahaan, jika tidak dibarengi dengan strategi pemasaran yang tepat maka tidak akan mampu mencapai tujuan laba perusahaan. Apalagi di tengah sengitnya persaingan bisnis saat ini, penting bagi setiap orang dan organisasi untuk mempelajari ilmu pemasaran. Kotler dan Amstrong (2012:29) mendefinisikan pemasaran sebagai proses yang diciptakan perusahaan untuk menciptakan nilai untuk konsumen dan membangun hubungan yang kuat dengan konsumen dengan tujuan untuk memperoleh nilai dari konsumen sebagai kembalinya. 
Sedangkan Hoffman dan Bateson (2002:4) mendefinisikan jasa sebagai usaha, perbuatan, atau penampilan.

Jasa dan barang memiliki karakteristik yang berbeda, sehingga membutuhkan strategi pemasaran yang berbeda pula. Menurut Kotler dan Amstrong (2010:268) sebuah perusahaan perlu mempertimbangkan empat karakteristik spesial jasa ketika mendisain program-program pemasaran, antara lain:

1. Jasa tidak berwujud (intangibility)

2. Jasa bersifat tak terpisahkan (separability)

3. Jasa bervariasi (variability)

4. Jasa bersifat mudah musnah (perishable)

\section{Pemasaran Rural}

\section{CKS Consulting} (2008) menggambarkan pasar urban di Indonesia yaitu termasuk Kotamadya, kabupaten, dan tempat-tempat lainnya dengan karakteristik urban (perkotaan), sedangkan yang lainnya dianggap sebagai rural. Mereka menambahkan jika ingin memenuhi kebutuhan rural market, penting bagi pebisnis untuk mengidentifikasi ukuran pasar dan lokasinya. Selain itu, penting pula untuk memahami lika-liku kehidupan penduduk "rural" agar dapat menciptakan produk yang sesuai dengan permintaan dan kapasitas pengeluaran mereka. Kehadiran suatu merek pada acara-acara di desa seperti pernikahan atau pameran akan membantu merek tersebut semakin dikenal oleh segmen besar populasi rural. Menyeponsori atau mengorganisir aktivitas di desa juga membantu dalam membangun merek sebagai integral dari gaya hidup rural market. Artinya, perusahaan dapat mengidentifikasi jenis-jenis acara dan tanggal-tanggal penting di target rural market dan menciptakan kegiatan dengan memanfaatkan promosi massa.

Neuwirth (2012) memaparkan beberapa tantangan memasarkan produk ke "rural area". Salah satunya adalah konsumen rural sulit percaya pada merek-merek baru. Oleh karena itu, pertama-tama perusahaan yang menjual barang atau jasa harus membangun kepercayaan dengan konsumen.

\section{Keputusan Pembelian}

Hoffman dan Bateson (2002:82) membagi proses pengambilan keputusan konsumen dalam tiga (3) tahap yaitu 1) tahap sebelum pembelian (pre-purchase stage), 2) tahap penggunaan (consumption stage), 3) tahap evaluasi pasca pembelian (post purchase evaluation stage). Untuk memasarkan jasa secara efektif, manajer pemasaran perlu untuk memahami proses berpikir yang digunakan oleh konsumen dalam setiap tahap proses keputusan konsumen.

\section{Bauran Pemasaran Jasa}




\section{Produk (X1)}

Kotler dan Amstrong (2011:224) mendefinisikan produk sebagai segala sesuatu yang bisa ditawarkan kepada suatu pasar untuk menarik perhatian, diakuisisi, digunakan atau dikonsumsi yang dapat memuaskan suatu kebutuhan atau keinginan.

Ketika perusahaan mampu menciptakan produk sesuai kebutuhan dan keinginan target konsumen, bahkan dengan menawarkan nilai lebih kepada konsumen, maka mereka akan puas. Kepuasan konsumen berdampak positif kepada perusahaan karena konsumen yang puas memiliki kecendrungan untuk membagikan pengalaman positif mereka ke 5-6 orang di sekeliling mereka, melakukan pembelian ulang, mencoba produk lain yang ditawarkan perusahaan, dan condong menjadi loyal (Bowen dan Chen, 2001; Kotler dan Keller, 2009:10).

H1: Produk (X1) berpengaruh positif dan signifikan terhadap keputusan pembelian (Y)

\section{Harga (X2)}

Kotler dan Amstrong (2012:52) mendefinisikan harga sebagai nilai uang yang harus dibayarkan oleh konsumen untuk memperoleh suatu produk.

Menurut Kenesei dan Todd (2003), harga adalah salah satu dari beberapa biaya yang dihadapi oleh pembeli. Biaya-biaya lain termasuk biaya waktu, biaya emosional, biaya tenaga dan lain sebagainya. Namun, harga merupakan biaya yang paling mudah dinilai oleh pembeli, sehingga memegang peranan penting dalam keputusan pembelian. Sejalan dengan itu, Ulbinaite et al. (2013) menyimpulkan bahwa kurangnya atau tidak adanya persepsi kebutuhan akan asuransi dan kurangnya atau tidak adanya persepsi keterjangkauan harga asuransi dapat menyesatkan perilaku konsumen terhadap asuransi. Dimensi moneter merupakan dimensi yang paling signifikan dalam menentukan keputusan pembelian asuransi. Sedangkan dimensi-dimensi lainnya seperti sosial, psikologikal dan emosional berperan kurang krusial dalam keputusan pembelian asuransi.

H2: Harga (X2) berpengaruh positif dan signifikan terhadap keputusan pembelian (Y)

\section{Tempat (X3)}

Kapoor et al. (2011:80) mendefinisikan tempat (place) sebagai segala aktivitas yang dilakukan oleh pembuat barang atau jasa untuk mencapai konsumen di tempat yang paling mudah dan nyaman diakses sekaligus menawarkan kepuasan pada level harga yang disetujui bersama konsumen. 
Kapoor dan Paul (2008) dalam Kapoor et al. (2011:80) menyatakan bahwa konsumen akan membeli barang atau jasa di tempat yang mudah diakses sekaligus menonjolkan atau menawarkan tingkat kepuasan yang lebih tinggi dibandingkan waktu dan tenaga yang harus ia habiskan.

H3: Tempat (X3) berpengaruh positif dan signifikan terhadap keputusan pembelian (Y)

\section{Promosi (X4)}

Kotler dan Keller (2009:539) menyatakan promosi adalah suatu bentuk komunikasi pemasaran, sedangkan komunikasi pemasaran adalah aktifitas pemasaran yang berusaha menyebarkan informasi, mempengaruhi atau membujuk kemudian mengingatkan target market atas perusahaan dan produknya agar bersedia, menerima, membeli dan setia pada produk yang ditawarkan oleh perusahaan tersebut.

Tanner dan Raymond (2012:363) menjabarkan ada enam (6) bauan promosi antara lain:
a. Iklan
b. Personal selling;
c. Sales promotion;
d. Public relations
e. Publicity;

\section{f. Direct marketing}

Dastak dan Aligholi

(2014) menemukan bahwa promotion and training berpengaruh signifikan dan merupakan variabel dominan yang mempengaruhi keputusan pembelian polis asuransi jiwa di Iran. Menurut mereka, karena kebanyakan orang tidak terlalu familiar dengan asuransi jiwa dan lemahnya budaya penggunaan asuransi jiwa, membuat promosi penting untuk membuat konsumen pertama sadar tentang manfaatnya.

H4: Promosi (X4) berpengaruh positif dan signifikan terhadap keputusan pembelian (Y)

\section{Orang (X5)}

Shameem dan Gupta (2012) mendefiniskan orang (people) sebagai konsumen, karyawan, manajemen dan semua orang yang terlibat di dalam organisasi. Penting bagi setiap orang untuk menyadari bahwa reputasi merek berada di tangan “orang”. Dari definisi-definisi di atas, tergambarkan bagaimana pentingnya orang dalam bauran pemasaran jasa karena mereka yang berperan dalam penyampaian jasa. Sehingga baik dan buruknya cara penyampaian jasa akan mempengaruhi persepsi konsumen terhadap produk yang ditawarkan dan citra perusahaan. 
H5: Orang (X5) berpengaruh positif dan signifikan terhadap keputusan pembelian (Y)

\section{Proses (X6)}

Zeithaml dan Bitner (2000:20) dalam Lilianti (2013) mendefinisikan proses sebagai semua prosedur aktual, mekanisme dan aliran aktivitas yang digunakan untuk menyampaikan jasa.

Dalam konteks asuransi jiwa, proses merupakan tahapan mulai dari nasabah mengajukan proposal asuransi hingga pengajuan klaim. Berdasarkan hasil penelitian terdahuu oleh Lilianti (2013), proses berpengaruh signifikan terhadap keputusan nasabah memilih asuransi jiwa.

H6: Proses (X6) berpengaruh positif dan signifikan terhadap keputusan pembelian (Y).

\section{Bukti Fisik (X7)}

Menurut Rao (2011:261), bukti fisik adalah apa yang secara fisik dimiliki perusahaan untuk konsumen. Itu termasuk lingkungan fisik outlet jasa, eksterior, interior, seluruh tanda-tanda fisik seperti peralatan, furnitur, alat tulis, papan nama, sertifikat, personil dan sebagainya.

Menurut Zeithml dan Bitner (2004) dalam Lilianti (2013), bukti fisik adalah suatu hal yang secara nyata turut mempengaruhi keputusan konsumen untuk membeli dan menggunakan produk jasa yang ditawarkan.

H7: Bukti fisik (X7) berpengaruh positif dan signifikan terhadap keputusan pembelian (Y)

\section{METODE PENELITIAN}

\section{Definisi Operasional}

1. Produk (X1) adalah sesuatu yang ditawarkan oleh perusahaan asuransi yaitu program perlindungan jiwa dan rencana keuangan masa depan dalam bentuk polis asuransi jiwa. Indikatornya adalah (Kotler dan Keller, 2009:178):
a. Nama merek
b. Citra produk
c. Ragam manfaat yang ditawarkan

d. Kualitas produk

2. Harga (X2) adalah nilai uang (premi) yang dibayarkan nasabah untuk mendapatkan polis asuransi jiwa. Indikatornya adalah (Kotler dan Keller, 2009:178):
a. Keterjangkauan premi
b. Metode pembayaran yang ditawarkan
c. Frekuensi pembayaran
d. Fasilitas cuti premi

3. Tempat (X3) adalah lokasi kantor representatif untuk menyediakan 
produk asuransi jiwa kepada nasabah dan potensial nasabah. Indikatornya adalah (Kapoor, et. al, 2011:73):
a. Lokasi kantor strategis
b. Lokasi kantor mudah diakses

4. Promosi adalah bauran promosi dan media yang digunakan perusahaan asuransi untuk mengkomunikasikan produk asuransi jiwa yang ditawarkan. Indikatornya adalah (Tanner dan Raymond, 2012) :

a. Penggunaan promosi penjualan

b. Penggunaan personal selling

c. Penggunaan iklan di media internet

d. Penggunaan iklan di media cetak

5. Orang (X5) adalah seluruh karyawan yang terlibat dalam proses penyajian jasa kepada nasabah. Indikatornya adalah (Kapoor, et al., 2011):
a. Keandalan agen
b. Kecepatan pelayanan
c. Pengetahuan agen tentang produk
d. Konsultasi yang diberikan agen
e. Empati karyawan

6. Proses (X6) adalah metode, proses, dan prosedur yang diciptkaan perusahaan asuransi untuk menyampaikan jasa kepada nasabah. Indikatornya adalah:

a. Prosedur registrasi b. Proses pencetakan polis

c. Prosedur pembayaran premi lanjutan

d. Prosedur Klaim

e. Proses pencairan klaim

7. Bukti fisik (X7) adalah hal-hal berwujud yang dimiliki perusahaan asuransi jiwa untuk meyakinkan nasabah dan nasabah potensial tentang jasa yang ditawarkan. Indikatornya adalah (Rao, 2011:261):
a. Ketersediaan parkir
b. Penampilan karyawan
c. Tata ruang kantor
d. Isi perjanjian buku polis

8. Keputusan membeli (Y) merupakan hasil dari adanya masalah dan/atau peluang. Dalam hal ini masalahnya adalah kebutuhan akan rasa tenang/perlindungan finasial. Indikatornya adalah (Kotler dan Keller, 2009:178):
a. Motivasi nasabah
b. Ingatan nasabah
c. Pembelajaran nasabah
d. Persepsi nasabah

Teknik Pengumpulan Data, Populasi dan Sampel, serta Alat Analisis

Penelitian ini menggunakan pendekatan kuantitatif bersifat eksplanatif (explanatory 
research) karena ingin mengidentifikasi hubungan antara variabel independen terhadap variabel dependen. Teknik pengumpulan datanya adalah melalui pendistribusian kusioner dan studi kepustakaan.

Populasi dalam penelitian ini adalah seluruh nasabah salah satu perusahaan asuransi jiwa asal Swiss yang berada di 3 kecamatan di Kabupaten Kutai Kartanegara, Kalimantan Timur yaitu 334 orang, dimana ditarik berdasarkan dengan kriteria-kriteria sebagai berikut:

1. Merupakan pemegang polis (termasuk beneficiary owner) karena pemegang polis dan beneficiary owner adalah orang yang umumnya sebagai pengambil keputusan dan pembayar premi;

2. Minimal telah menjadi nasabah selama minimal satu (1) tahun karena dianggap telah memiliki pengalaman yang dapat menjadi dasar evaluasi.

Dalam penentuan sampel, kami menggunakan rumus Slovin dengan tingkat kesalahan $\mathrm{e}=10 \%$ didapatkan 76,95 sehingga untuk mempermudah penelitian, maka dilakukan pembulatan menjadi 80 subjek. Teknik pengambilan sampel pada penelitian ini adalah proportionate stratified sampling dimana perbandingan jumlah antara nasabah di Tenggarong, Sebulu dan Kota Bangun adalah $4: 3: 1$.

Selanjutnya, seluruh data yang terkumpul dan dianggap layak, dianalisis dengan regresi linear berganda, dimana sebelumnya melalui uji asumsi klasik untuk memastikan terpenuhinya syarat Ordinary Least Square (OLS).

\section{HASIL ANALISIS}

Dari 80 kuisioner yang didistribusikan, hanya 76 buah yang kembali dan layak untuk dianalisis lebih lanjut.

\section{a. Uji Kelayakan Model (Uji F)}

Sebelum mengarah pada pengujian hipotesis, dilakukan uji kelayakan model (goodness of fit) dengan uji $\mathrm{F}$ untuk mengidentifikasi apakah model regresi yang diestimasi layak digunakan untuk menjelaskan pengaruh variabel-variabel independen terhadap variabel dependen.

\section{Tabel 1: Hasil Uji F}

\begin{tabular}{lrrrrrr}
\hline & Sum of & \multicolumn{4}{c}{ Mean } \\
Model & Squares & df & Square & $F$ & Sig. \\
\hline 1 & Regressio & & & & & \\
$\mathrm{n}$ & 94.602 & 7 & 13.515 & 16.174 & $.000^{\mathrm{b}}$ \\
\hline Residual & 56.819 & 68 & .836 & & \\
\hline Total & 151.421 & 75 & & & \\
\hline
\end{tabular}

a. Dependent Variabel: keputusan_pembelian 
b. Predictors: (Constant), bukti_fisik, proses, produk, orang, tempat, promosi, harga

Berdasarkan tabel di atas, diketahui bahwa nilai $\mathrm{F}_{\text {hitung }}$ dari model adalah 16.174. Sementara itu, dengan derajat kebebasan (df) $=(\mathrm{n}-\mathrm{k})$, dan $(\mathrm{k}-1)$ yaitu 68 (df penyebut) dan 7 (df pembilang), ditemukan nilai $\mathrm{F}_{\text {tabel }}=2.15$. Selain itu, nilai signifikansi model lebih kecil dari taraf nyata $\alpha 0.1 \quad(\mathrm{p}=0.000<0.1)$ dan Fhitung > Ftabel $(16.174>2.15)$. Artinya syarat kelayakan model regresi yang diajukan penelitian ini terpenuhi.

\section{b. Uji Pengaruh Parsial (Uji t)}

\section{Tabel 2: Hasil Uji t}



Berdasarkan tabel 2, dapat disimpulkan bahwa H1, H2, H3, H5, H7 terbukti kebenarannya, sedangkan H4 dan H6 ditolak. Jika ditinjau dari nilai standardized coefficient, secara berurutan adalah harga (X2), diikuti oleh bukti fisik (X7), orang (X5), produk (X1), tempat (X3), proses (X6), dan promosi (X4). Artinya, harga (X2) adalah variabel yang berpengaruh dominan terhadap keputusan pembelian asuransi jiwa (Y).

\section{c. Analisis Hubungan dan Pengaruh Bauran Pemasaran terhadap}

\section{Keputusan Pembelian}

\section{Tabel 3: $\mathbf{R}$ dan $\mathbf{R}^{2}$}

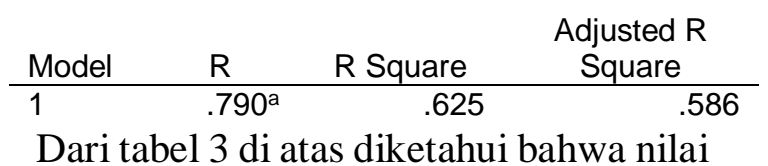

koefisien korelasi (R) adalah 0.790. Artinya, hubungan antara bauran pemasaran jasa 7P secara bersama-sama (simultan) terhadap keputusan pembelian tergolong kuat.

Selanjutnya, juga diketahui bahwa nilai koefisien determinasi $\left(\mathrm{R}^{2}\right)$ adalah 0.625, artinya besarnya pengaruh yang dijelaskan oleh bauran pemasaran jasa $7 \mathrm{P}$ yang dimasukkan ke dalam model terhadap keputusan pembelian asuransi jiwa adalah $62.5 \%$, sedangkan sisanya sebesar $37.5 \%$ dijelaskan oleh variabel-variabel lain yang tidak dimasukkan ke dalam model.

\section{PEMBAHASAN DAN KESIMPULAN}

Hasil penelitian ini secara tegas mendukung penelitian Ulbinaite et al. (2013) yang menandai bahwa kurangnya atau tidak adanya persepsi kebutuhan akan 
asuransi dan kurangnya atau tidak adanya persepsi keterjangkauan harga asuransi dapat menyesatkan perilaku konsumen terhadap asuransi. Dimensi moneter merupakan dimensi yang paling signifikan dalam menentukan keputusan pembelian asuransi. Oleh karena itu, perusahaan asuransi perlu meramu beberapa produk yang ditujukan kepada beberapa segmen konsumen. Edukasi tentang perencanaan keuangan juga perlu terus dilakukan kepada nasabah sehingga mereka bisa melihat produk asuransi jiwa sebagai hal penting dan mempersepsikan harga/premi yang dibayarkan adalah wajar.

Selanjutnya, ditemukan bahwa promosi menunjukkan pengaruh paling rendah dan secara parsial tidak signifikan terhadap keputusan pembelian asuransi jiwa. Hal ini tidak mengkonfirmasi penelitian terdahulu (Dastak dan Aligholi, 2014; Lilianti 2013) karena kegiatankegiatan promosi perusahaan asuransi jiwa masih mengarah ke berita di internet, media cetak dan baliho di tempat-tempat strategis di kota-kota besar sehingga jarang terdengar oleh mereka yang berada di daerah rural. Oleh karena itu, menurut CKS Consulting (2008), kehadiran suatu merek pada acara-acara di desa seperti pernikahan atau pameran akan membantu merek tersebut semakin dikenal oleh segmen besar populasi rural. Menyeponsori atau mengorganisir aktivitas di desa juga membantu dalam membangun merek sebagai integral dari gaya hidup rural market.

Untuk pengembangan, penelitian mendatang dapat menambahkan variabelvariabel lain seperti penagruh agama, literasi finansial dan WOM ke dalam model. Menurut Ifejinou dan Emmanuel (2013), agama telah menjadi faktor penting yang membentuk persepsi seseorang tentang kehidupan. Berdasarkan hasil penelitian mereka ditemukan bahwa meskipun Islam mempengaruhi permintaan asuransi jiwa, namun efeknya sangat kecil.

Penelitian mendatang juga dapat memperbesar jumlah sampel atau mengubah setting lokasi di kota besar di Indonesia untuk melihat jika ada perbedaan temuan antara konsumen rural dan konsumen urban.

\section{DAFTAR PUSTAKA}

CKS Consulting. 2008. Rural Marketing Practices for Telecom Services. Nokia Siemens Network. (Online) (http://cks.in/wpcontent/uploads/2012/10/RuralMarketi ngPractices.pdf , Diakses Pada Januari 2019). 
Cordell, David M. dan Langdon, Thomas P. 2009. Life Insurance in Times of Uncertainty. Journal of Financial Planning. (Online). (https://www.massmutual.com/mmfg/p df/journalfp_090109.pdf Diakses Pada 03 Januari 2019)

Dastak, A.G., Aligholi, M. 2014. Investigation of the Impact of Marketing mix (8p) on Insurance Policy Purchase in Mellat Insureance Company in Alborz Province, Iran. Journal of Applied Environmental and Biological Sciences. 4(11). pp. 100-106.

Hoffman, K. D. dan Bateson, John E.G. 2002. Essentials of Services Marketing: Concepts Strategies, \& Cases, $2^{\text {nd }}$ ed. Texas: Harcourt College Publishers.

Ifejionu, N.S. dan Emmanuel, B. B. 2013. Impact of Islamic Belief on the Demand for Life Insurance Policies in Lagos State, Nigeria. Asian Economic and Financial Review. 4(2). pp. 191-198.

Kapoor, Ramneek et al. 2011. Services Marketing: Concept \& Practices. New Delhi. Tata McGraw Hill Education Private Limited.

Kenesei, Zsofia dan Todd, Sarah. 2003. The Use of Price in The Purchase Decision. Journal of Empirical Generalisations in Marketing Science. pp. 1-21.

Kotler, Philip dan Amstrong, Gary. 2012. Principles of Marketing, $14^{\text {th }}$ ed. London: Pearson Education Limited.

Kotler, Philip dan Keller, Kevin L. 2009. Manajemen Pemasaran, Edisi Ketiga Belas Jilid 1. Terjemahan Sabran, Bob. 2009. Jakarta: Erlangga.

Lilianti. 2013. Analisis Variabel-Variabel Yang Mempengaruhi Keputusan
Nasabah Memilih Asuransi Prudential Pada Kantor Agency Prureality di Samarinda. Tesis. Samarinda: Program Pasca Sarjana Universitas Mulawarman

Neuwirth, Benjamin. 2012. Marketing Channel Strategies in Emerging Rural Markets: Unlocking Business Potential. Kellogg School of Management.

Rao, K. Rama Mahana. 2011. Service Marketing, $2^{\text {nd }}$ ed. New Delhi: Pearson India.

Razdan, R., Das, M., dan Sohoni, A. 2014. The Evolving Indonesian Consumer. McKinsey \& Company. (Online). (https://www.mckinsey.com/businessfunctions/marketing-and-sales/ourinsights/the-evolving-indonesianconsumer, Diakses Pada Januari 2019)

Shameem, Beenish dan Gupta, Sameer. 2012. Marketing Strategies in Life Insurance Services. International Journal of Marketing, Financial Services and Management Research. 1(11). pp. 132141.

Sukotjo, H. dan A. Radix, S. 2010. Analisis Marketing Mix-7P (Produk, Price, Promotion, Place, Participant, Process dan Physical Evidence) terhadap Keputusan Pembelian Produk Klinik Kecantikan Teta di Surabaya. Jurnal mitra Ekonomi dan Manajemen Bisnis. 1(2). pp. 216-228.

Tanner, Jeff dan Raymond, Mary A. 2012. Marketing Principles. New Jersey: Pearson Prentice Hall.

Ulbinaite, A., Kucinskiene, M. dan Le Moullec, Y. 2013. Determinants of Insurance Purchase Decision in Lithuania. Engineering Economics. 24(2). pp.144-1 